\title{
Molecular Cloning of Bone Morphogenetic Protein (BMP) Gene from the Planarian Dugesia japonica
}

\author{
Hidefumi Orii ${ }^{\star}$, Kentaro Kato, Kiyokazu Agata \\ and Kenji Watanabe \\ Laboratory of Regeneration Biology, Department of Life Science, Faculty of Science, \\ Himeji Institute of Technology, Harima Science Garden City, Akou, Hyogo 678-1297, Japan
}

\begin{abstract}
BMP (Bone Morphogenetic Protein) acts as a morphogen for dorso-ventral patterning and organogenesis in both vertebrate and invertebrate development. A cDNA encoding BMP (named Djbmp) has been cloned and sequenced from the planarian Dugesia japonica. The mature form of DjBMP which was deduced from the cDNA sequence was composed of 114 amino acid residues. The position of seven cysteine residues of the mature DjBMP was highly conserved among the TGF- $\beta$ superfamily. DjBMP had high similarity to human BMP-2A (50\% amino acid identity), BMP-4 (49\%) and Drosophila decapentaplegic protein $(48 \%)$, indicating that DjBMP belongs to DVR (decapentaplegic-Vg1-related) group. The expression pattern in intact and regenerating planarians revealed by whole mount in situ hybridization suggested that the DjBMP plays a role not only in dorso-ventral but also in mid-lateral body patterning.
\end{abstract}

\section{INTRODUCTION}

Transforming growth factor- $\beta$ (TGF- $\beta$ ) superfamily is a large group including biological active proteins such as activin, inhibin, growth/differentiation factor (GDF) and bone morphogenetic proteins (BMPs) (Horgan et al., 1994; Kingsley, 1994). One of the members, BMP-4, was found to act as a morphogen for ventralization in vertebrate development (Dale et al., 1992; Jones et al., 1992; Dosch et al., 1997). In Drosophila, decapentaplegic (dpp) gene which encodes a BMP-4 homologue has been known to play a key role in determination of dorsalization during the early development (Irish and Gelbart, 1987). The idea that the dorso-ventral (D-V) axis in deuterostomes including vertebrate corresponds to the ventro-dorsal axis in protostomes including arthropod is supported by molecular evidence that DPP and BMP-4 are functionally similar in inducing ventral structure in frog (deuterostome) and dorsal structure in fly (protostome), respectively (Holley et al., 1995; Horgan, 1995; De Robertis and Sasai, 1996).

The freshwater planarian Dugesia japonica, belonging to the Phylum Plathelminthes has powerful activity for regeneration (for review; Baguñà et al., 1994). We are interested in how body plan is established during the planarian regeneration. As for the antero-posterior axis in planarians, the expression of Hox/HOM-C genes may be important (Orii et al., in preparation). On the other hand, we have no information on their $\mathrm{D}-\mathrm{V}$ patterning. In this study, we focused on a planarian BMP-4/DPP homologue as a candidate molecule in D-V pat-

\footnotetext{
* Corresponding author: Tel. $+81-7915-8-0187$; FAX. $+81-7915-8-0187$
}

terning. The molecular cloning of the BMP gene and its expression in intact and regenerating planarians are reported.

\section{MATERIALS AND METHODS}

\section{Organisms}

All planarians in this study were derived from one worm of Dugesia japonica collected in Irima river in Gifu, Japan and maintained clonally in our laboratory (clonal population GI) (Orii et al., 1993). Amputated worms were regenerated in autoclaved tap water at about $22^{\circ} \mathrm{C}$.

\section{cDNA cloning and sequencing}

A cDNA library $\left(4 \times 10^{6}\right.$ in size $)$ was constructed from poly $\mathrm{A}^{+}$ RNA of whole worms using $\lambda$ ZAPII vector (Umesono et al., 1997). The mixture $(10 \mu \mathrm{l})$ for PCR (polymerase chain reaction) contained 1 $\times$ Taq buffer (10 mM Tris- $\mathrm{HCl} \mathrm{pH} 8.3,50 \mathrm{mM} \mathrm{KCl}, 1.5 \mathrm{mM} \mathrm{MgCl} 2)$, Takara Taq polymerase (Takara, $0.025 \mathrm{U} / \mu \mathrm{l})$, dNTPs ( $0.25 \mathrm{mM}$ each), $D$. japonica total DNA (about $40 \mathrm{ng} / \mu \mathrm{l}$ ) and a set of degenerate primers (1 pmole/ $\mu$ l each): a forward primer 5'-GGITGG(A/G/C)AIGA (C/T)TGG(G/A)TIGCICC-3' and a reverse primer $5^{\prime}-A C I A(G / A) I G T$ (T/C)TGIA(C/G)IA(T/C)IGC(G/A)TG(G/A)TT-3' corresponding to amino acids $G W(N / D / Q) D W(I / V)(I / V) A P$ and $N H A(I / V) V Q T L V$, respectively. The reaction conditions were as follows: an initial denaturation at $94^{\circ} \mathrm{C}$ for $1 \mathrm{~min}$ followed by 40 cycles of $94^{\circ} \mathrm{C}$ for $1 \mathrm{~min}, 45^{\circ} \mathrm{C}$ for $1 \mathrm{~min}, 72^{\circ} \mathrm{C}$ for $1 \mathrm{~min}$ and a final elongation step at $72^{\circ} \mathrm{C}$ for $5 \mathrm{~min}$. The PCR product (about $120 \mathrm{bp}$ ) was extracted from $6 \%$ acrylamide gel, amplified again, cloned into pT7blue T vector (Novagen) and sequenced. From the sequence of the PCR product corresponding to BMP, we designated a specific forward primer 5'-CGTATCCGTTATCAGATAATTTTAA-3' (arrow in Fig.1) and screened the CDNA library by PCR with the primer and M13 universal primer 5'-CGCCAGGGTTTTCCCAGTCACGAC-3' (Watanabe et al., 1997). Out of 11 positives, one clone carrying the longest insert ( $\mathrm{pDjBMP17}$ ) has been sequenced as to both strands by using Thermo Sequenase cycle sequencing kit (Amersham) and automatic DNA sequencer DSQ1000L (Shimadzu). 


\section{Southern blot hybridization}

D. japonica total DNA $(10 \mu \mathrm{g})$ was digested with EcoRI or Spel, subjected to $0.8 \%$ agarose gel electrophoresis, and blotted on Hybond $\mathrm{N}^{+}$membrane (Amersham). The membrane were prehybridized in 6 $\times$ SSC, $5 \times$ Denhardt's solution, $1 \%$ SDS, $100 \mu \mathrm{g} / \mathrm{ml}$ salmon testes DNA at $65^{\circ} \mathrm{C}$ for $1 \mathrm{hr}$ and hybridized in the same solution with probe. pDjBMP17 DNA was labeled by using random primed labeling kit (Takara) with $\alpha-\left[{ }^{32} \mathrm{P}\right]-\mathrm{dCTP}$ (Amersham, $\sim 3000 \mathrm{Ci} / \mathrm{mmol}$ ) and used as the hybridization probe. The membrane was washed twice in $2 \times$
SSC, $0.1 \%$ SDS at $65^{\circ} \mathrm{C}$ for $30 \mathrm{~min}$ and exposed to film with an intensifying screen.

\section{Whole mount in situ hybridization}

The digoxygenin (DIG) labeled anti-sense and sense RNA probes were synthesized with T7 RNA polymerase and T3 RNA polymerase, respectively, and used for hybridization without alkaline hydrolysis (Umesono et al., 1997; Agata et al., 1998).

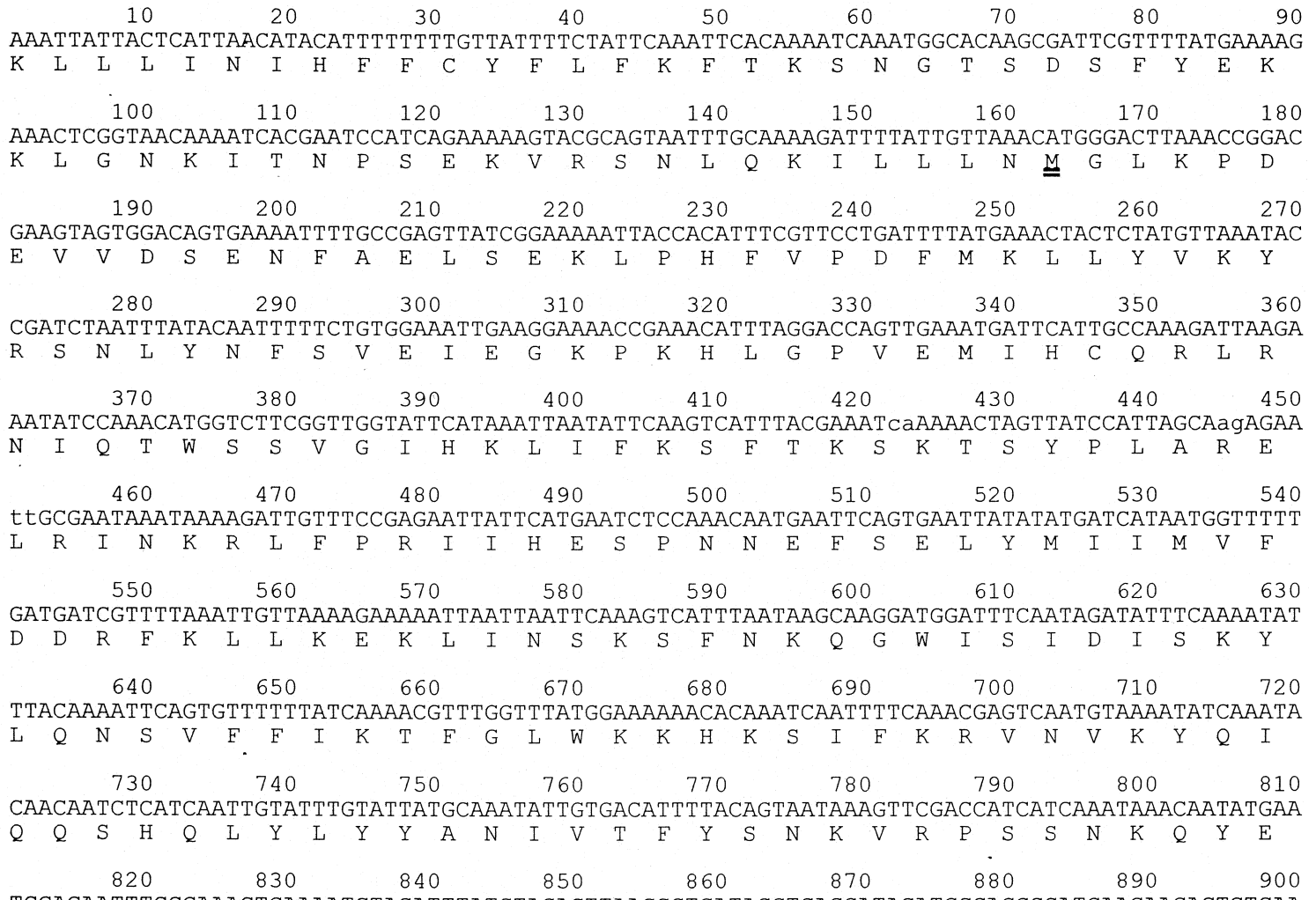
TCGACAATTTCCGAAACTGAAAATCTACATTTATCTAGAGTTAAGCGTGATACGTCAGGATACATGCCAGGCCATGAAGAAGACTGTCAA

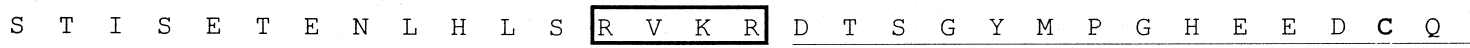

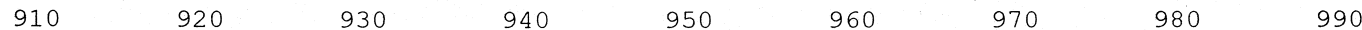
AGATATCCTTTAATTGTTACTTTTAAAGAAGTTGGATGGAGCAAATGGATAATTGCACCCCAAAACTATAATGCTTATTATTGTAAAGGT $\begin{array}{lllllllllllllllllllllllllllllll}R & Y & P & L & I & V & T & F & K & E & V & G & W & S & K & W & I & I & A & P & Q & N & Y & N & A & Y & Y & C & K & G\end{array}$

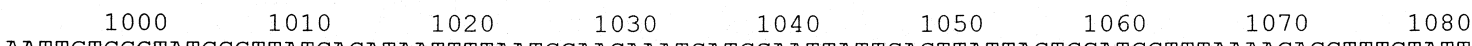
AATTGTCCGTATCCGTTATCAGATAATTTTAATGCAACAAATCATGCAATTATTCAGTTATTAGTGCATGGTTTAAAAGACCTTTCTATT $\begin{array}{llllllllllllllllllllllllllllllllll}N & C & P & Y & P & L & S & D & N & F & \text { (N) (A) (T) } & N & H & A & I & I & Q & L & L & V & H & G & L & K & D & L & S & I\end{array}$

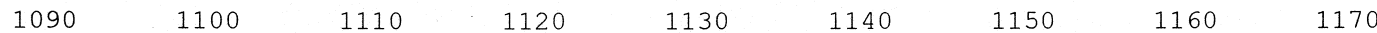
CCAAAACCGTGCTGTGTGCCTTATCACTTACACCCAGAAACTTTATTATATTTAAACAATGAAGGCGATGCACTTTTGCGTGAATTCAAA \begin{tabular}{llllllllllllllllllllllllllllllll}
$\mathrm{P}$ & $\mathrm{K}$ & $\mathrm{P}$ & $\mathrm{C}$ & $\mathrm{C}$ & $\mathrm{V}$ & $\mathrm{P}$ & $\mathrm{Y}$ & $\mathrm{H}$ & $\mathrm{L}$ & $\mathrm{H}$ & $\mathrm{P}$ & $\mathrm{E}$ & $\mathrm{T}$ & $\mathrm{L}$ & $\mathrm{L}$ & $\mathrm{Y}$ & $\mathrm{L}$ & $\mathrm{N}$ & $\mathrm{N}$ & $\mathrm{E}$ & $\mathrm{G}$ & $\mathrm{D}$ & $\mathrm{A}$ & $\mathrm{L}$ & $\mathrm{L}$ & $\mathrm{R}$ & $\mathrm{E}$ & $\mathrm{F}$ & $\mathrm{K}$ \\
\hline
\end{tabular}

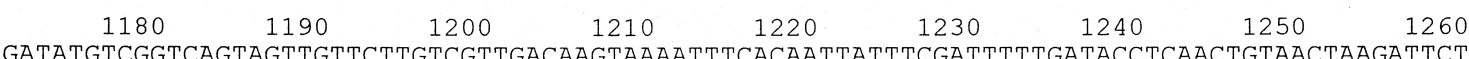
$\begin{array}{llllllllllllllll}D & M & S & V & S & S & C & S & C & R & *\end{array}$

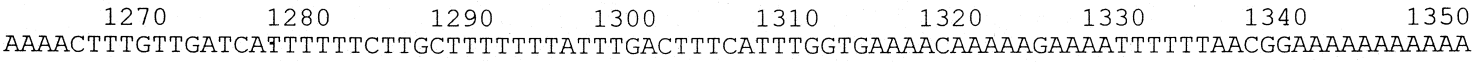
1360

AAAAAA

Fig. 1. Nucleotide sequence of Djbmp cDNA (upper) and the deduced amino acid sequence (lower). The first methionine is double underlined. Seven cysteine residues conserved among the members of TGF- $\beta$ superfamily are in bold. The box shows the consensus sequence of proteolytic cleavage. The predicted mature form is underlined. The potential asparagine-linked glycosylation sites are circled. The arrow shows the specific primer used for PCR screening of the cDNA library. The amino acids are shown with single letter abbreviations. 


\section{RESULTS AND DISCUSSION}

We have aligned many members of TGF- $\beta$ superfamily to designate a set of degenerate primers for PCR (see Materials and Methods). Using the primers, PCR was performed with $D$. japonica total DNA. Cloning and sequencing analysis revealed that only one PCR fragment had similarity with BMP genes. A cDNA library was screened by the stepwise dilution method with a specific primer designed for the sequence of PCR product (Watanabe et al., 1997). The positive cDNA clone with the longest insert (pDjBMP17) was sequenced (Fig. 1). The longest open reading frame (ORF) from the 5 ' end of the insert to the stop codon (nucleotide 1201-1203) was found. Although the first methionine in the ORF was found at nucleotide 163-165, it did not seem to be the initiation codon, because the upstream region of the methionine of the ORF did not contain any stop codons in frame and the N-terminal region of the deduced protein translated from the methionine did not contain many hydrophobic amino acid redisues, which may serve as signal sequence of secreted peptide such as BMP precursor (Nishimatsu et al., 1992). As the deduced protein was similar to the members of BMP group on the whole, we designated it DjBMP (Dugesia japonica BMP). In comparison with other proteins belonging to TGF- $\beta$ superfamily, the pro-protein of DjBMP might be processed into mature form by cleavage at the carboxyl end of $R$ (amino acid 286) of RVKR corresponding to the cleavage consensus sequence $R X X R$ (Panganiban et al., 1990). The position of seven cysteine residues conserved among the members of TGF- $\beta$ superfamily was also confirmed in the protein. Figure 2 shows the comparison of mature protein of DjBMP with other TGF- $\beta$ related proteins from the first cysteine to the carboxyl terminal. In this region, DjBMP protein was similar to human BMP-2A $(50 \%$ amino acid identity), BMP-4 (49\%), sea urchin univin (50\%), Drosophila DPP (48\%), Drosophila 60A (47\%), human BMP$5(44 \%)$, TGF- $\beta 1(33 \%)$ and inhibin- $\beta$ a (33\%). A putative Nlinked glycosylation site (NXT/S) was found at amino acid 341 343 (NAT), whose position was also conserved among 60A and DPP subclasses. These results indicate that DjBMP belongs to DVR (decapentaplegic- $\underline{V}$ 1-related) group of TGF- $\beta$ superfamily (Kingsley, 1994). It was very difficult to classify DjBMP more precisely even by the phylogenetic sequence analysis with Genetics Computer Group (GCG) program (Madison, Wisconsin), because the sequences of members of TGF$\beta$ superfamily are various for their length.

Genomic Southern hybridization probed with the Djbmp cDNA revealed that the Djbmp was a single copy (Fig. 3). PCR using genomic DNA as a template indicated that there was no intron in the region encoding mature protein as well as vertebrate BMP-4 gene (Kurihara et al., 1993) (data not shown).

To investigate the expression pattern of the gene, whole mount in situ hybridization was performed in intact worms (Fig. $4 \mathrm{~A}, \mathrm{~B}$ and $\mathrm{C}$ ). The Djbmp was expressed, though very weakly, in dorsal cells (Fig. 4A and B). No signal was detected with sense probe (data not shown). We never observed any sig- nals in the ventral side (Fig. 4C). The expression was stronger in the medial region. There has been no report of morphologically special cells whose distribution is the same as that of Djbmp expressing cells. Unfortunately, we could not identify what kind of cells expressed Djbmp, because of the sensitivity of our in situ hybridization method on paraffin embedded sections. In addition to sequence comparison (Fig. 2), the expression pattern suggests that DjBMP may be a homologue of DPP/BMP-4 in Drosophila and vertebrates. DjBMP may play a key role as a dorsal forming or anti-neurogenic factor in the planarian as well as DPP in Drosophila (Sasai et al., 1995; Wilson and Hemmati-Brivanlou, 1995). To elucidate the role of DjBMP in D-V patterning, one should investigate the expression pattern of $D j b m p$ during regeneration of dorsal and ventral parts. However, it is impossible to divide a flat worm into dorsal and ventral pieces.

The expression along the dorso-medial region suggests that $\mathrm{DjBMP}$ also plays some role in mid-lateral patterning of the dorsal side. The planarian Dugesia japonica has high regeneration ability and a piece of the body can regenerate completely. The left or right marginal fragment without medial region can also regenerate to a whole animal. We investigated the expression pattern of $D j b m p$ during regeneration from the lateral piece without the cells expressing $D j b m p$. One day after amputation, the cells expressing Djbmp appeared dispersedly and very weakly only on the dorsal side (Fig. 4D). On the second or third day, the positive cells were distributed mainly in the dorso-medial region (Fig. 4E). It was not until five days after amputation that a pair of small eyes and a phar$y n x$ appeared, indicating the formation of the medial structure. Djbmp expressing cells were distributed mainly on the curved dorso-medial region at this stage. Seven days after amputation, distinct eyes and pharynx were regenerated and the expressing cells were more clearly distributed on the dorsomedial region (Fig. 4F). The expression pattern is represented schematically in Fig. 4G. The expression before differentiation of bilateral eyes suggests that DjBMP is involved in midlateral patterning during regeneration. As we could not monitor the behavior of single cells during regeneration, we do not know if the expressing cells move into the midline during regeneration or not. The change of expression pattern during regeneration suggests that dynamic morphogenesis occurs throughout the remaining tissue after amputation rather than in the restricted regenerating region called 'blastema'. In other words, the planarian regeneration could be referred to as 'morphallaxis' rather than 'epimorhosis'. Furthermore, the quick response of the expression after amputation (after only 1day) also suggests that it may be involved in initial $D-V$ patterning which occurs before dorsal cell differentiation.

It is interesting that the Djbmp was expressed in both intact and regenerating worms, because $d p p / B m p-4$ gene is expressed and functions in early embryogenesis of fly and vertebrates. It is probable that $D j b m p$ is expressed in early embryogenesis as well as regeneration. If so, the mechanism of body planning in early embryogenesis may be maintained and utilized for regeneration in planarians. Furthermore, the 


\begin{tabular}{|c|c|c|c|c|c|c|}
\hline & 1 & fowaro & & & & reverse 60 \\
\hline D j BMP & CQRYPL I VTF & K. EV GWSKWI & $\overrightarrow{I A P} Q N Y N A Y Y$ & QKGNOPYPLS & DNFN. . . AT & $\overleftarrow{\text { NHA I IQLLVH }}$ \\
\hline hTGFb 1 & $-V-. Q-Y$ I D - & RKDL --. --- & $\mathrm{HE}-\mathrm{KG}-\mathrm{H}-\mathrm{NF}$ & $-\mathrm{L}-\mathrm{P}--\ldots$ & $\ldots$. IWSLD - & QYSKVLA-YN \\
\hline h T GF b 3 & $-V-.--Y$ I D - & RQDL--. - - V & $\mathrm{HE}-\mathrm{KG}-\mathrm{Y}-\mathrm{NF}$ & $-S-P$ & $\ldots$ LRSAD - & $T-S T V L G-Y N$ \\
\hline $\mathrm{h} I \mathrm{NH}-\mathrm{Ba}$ & $-K K \cdot Q F F-S-$ & $-. D I--N D--$ & $---\mathrm{SG}-\mathrm{H}-\mathrm{N}-$ & -SH I A & G. TSGSSLSF & HST V-NHYRM \\
\hline $\mathrm{h}$ INH-Bb & -RQ. QFF ID- & R. LI $--N D--$ & $---\mathrm{TG}-\mathrm{YGN}-$ & $-A Y-A$ & G. VPGSASSF & HT - VVNQYRM \\
\hline hBMP 5 & $-\mathrm{K} \mathrm{K} \mathrm{HE}-\mathrm{Y}-\mathrm{S}-$ & R. $D L--Q D--$ & $---E G-A-F-$ & $S F--N$ & $\mathrm{AHM}-\ldots .--$ & $----\mathrm{V}-\mathrm{T}---$ \\
\hline hBMP 6 & $-R K H E-Y-S-$ & Q. $D L--Q D--$ & $---\mathrm{K} G-\mathrm{A}-\mathrm{N}-$ & $\mathrm{SF}--\mathrm{N}$ & $\mathrm{AHM}-\ldots .--$ & $----\mathrm{V}-\mathrm{T}---$ \\
\hline hBMP 7 & - K K HE $-Y-S-$ & R. DL $--Q D--$ & $---\mathrm{EG}-\mathrm{A}---$ & $A F--N$ & SYM- ...-- & $-\cdots-\mathrm{V}-\mathrm{T}---$ \\
\hline suDVR 1 & $-\mathrm{K}-\mathrm{KN}-\mathrm{F}-\mathrm{N}-$ & E. DLD-QE-- & $---\mathrm{LG}-\mathrm{V}-\mathrm{F}-$ & $A F--N$ & $\mathrm{GHA}^{-} \ldots .--$ & $----\mathrm{V}-\mathrm{T}-\cdots$ \\
\hline $\mathrm{d} 60 \mathrm{~A}$ & $--M Q T-Y I D-$ & $-. \mathrm{DL}--\mathrm{HD}--$ & $---E G-G-F-$ & $N F--N$ & $\mathrm{AHM}-\ldots .-$ & $----\mathrm{V}-\mathrm{T}---$ \\
\hline $\mathrm{HrBMPa}$ & $-H-E E-Y-S-$ & Q. D-N-ED-- & $---S G-M--R$ & pF--- & $\mathrm{A}-\mathrm{M}-\ldots \ldots--$ & $----\mathrm{V}-\mathrm{T}---$ \\
\hline hBMP $2 A$ & $-K-H--Y-D-$ & S. D $---N D--$ & $\mathrm{V}--\mathrm{PG}-\mathrm{H}-\mathrm{F}-$ & $-F--A$ & $-\mathrm{HL}-\ldots \mathrm{S}-$ & $----\mathrm{V}-\mathrm{T}--\mathrm{N}$ \\
\hline hBMP 4 & $-\mathrm{R}-\mathrm{HS}-\mathrm{Y}-\mathrm{D}-$ & S. D---ND-- & $V--P G-Q-F-$ & $-F--A$ & $-\mathrm{HL}-\ldots \mathrm{S}-$ & $----V-T--N$ \\
\hline $\mathrm{dDPP}$ & $-\mathrm{R}-\mathrm{HS}-\mathrm{Y}-\mathrm{D}-$ & S. D---DD-- & $\mathrm{V}--\mathrm{LG}-\mathrm{D}---$ & $-F--A$ & $-\mathrm{H}^{--} \ldots \mathrm{S}-\mathrm{S}-$ & $---V V-T--N$ \\
\hline$x$ V G 1 & $-K K R H-Y-E-$ & $-. D---Q N-V$ & $----\mathrm{G}-\mathrm{M}-\mathrm{N}-$ & $----\mathrm{T}$ & $\mathrm{EIL}-\ldots \mathrm{GS}$ & $----\mathrm{L}-\mathrm{T}---$ \\
\hline suUN I V IN & $--H R-F-S-$ & R. D---EN-- & $---M G-Q---$ & $-F--G$ & $\mathrm{ERL}-\ldots \mathrm{G}^{-}$ & $------\mathrm{T}--\mathrm{N}$ \\
\hline hGDF 5 & $-\mathrm{S}-\mathrm{KA}-\mathrm{H}-\mathrm{N}-$ & $-. \mathrm{DM}--\mathrm{DD}--$ & $---\mathrm{LE}-\mathrm{E}-\mathrm{FH}$ & $E F--R$ & SHLE.... P- & $---\mathrm{V}--\mathrm{T}-\mathrm{MN}$ \\
\hline D ORSAL IN & $-\mathrm{R}-\mathrm{TS}-\mathrm{H}-\mathrm{N}-$ & $-.-\mathrm{I}--\mathrm{DS}--$ & $---\mathrm{KD}-\mathrm{E}-\mathrm{FE}$ & $F F--T$ & $--V T \ldots P-$ & $\mathrm{K}---\mathrm{V}-\mathrm{T}---$ \\
\hline hBMP 3 & $-A-R Y-K-D-$ & A. D I $---E_{--}$ & $-\mathrm{S}-\mathrm{KSF} \mathrm{D}---$ & $2 F-M P$ & KSLK....PS & $---\mathrm{T}--\mathrm{S} I-\mathrm{R}$ \\
\hline hGDF 1 & - RARR - Y - S- & R. $----H R-V$ & $-\cdots \mathrm{RGFL}-\mathrm{N}-$ & $A L-V A$ & LSGSGGPP-L & --- VLRA-M- \\
\hline $\mathrm{mNODAL}$ & $-R-V K F Q-D-$ & N. LI $--G S--$ & $-\mathrm{Y}-\mathrm{K} \mathrm{Q}----\mathrm{R}$ & $-N-V G$ & $\mathrm{EE}-\mathrm{H} \ldots \mathrm{P}-$ & $---Y--S-L K$ \\
\hline hMIS & $-A L R E-S-D L$ & RA-RSVL... & $-\because-E T-Q-N N$ & $G W-Q-$ & -RNPRYG. . & $--V V L L-K M Q$ \\
\hline
\end{tabular}

61

D jBMP

GLK. DLSIPK PCCVPYHLHP ETLLYLNNEG. DALLREFKD MSVSSOSGR \% identity

hTGFb 1

hTGFb 3

h I NH-Ba

$\mathrm{hINH}-\mathrm{Bb}$

hBMP 5

hBMP 6

hBMP 7

suDVR 1

d $60 \mathrm{~A}$

$\mathrm{HrBMPa}$

hBMP 2 A

hBMP 4

dDPP

$\mathrm{xVG1}$

suUNIVIN

hGDF 5

cDORSAL IN

hBMP 3

hGDF 1

mNODAL

hMIS

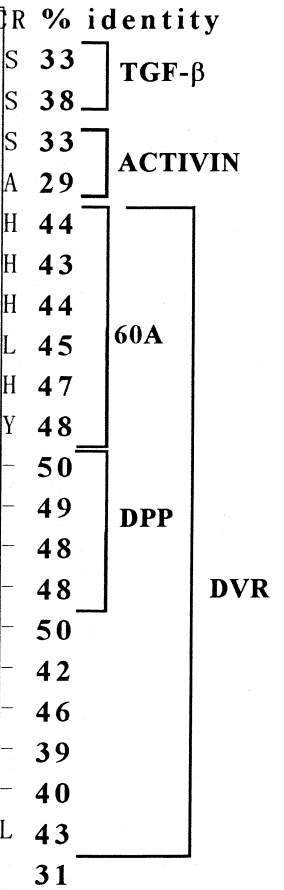

Fig. 2. A comparison of the amino acid sequence of the DjBMP with other members of TGF- $\beta$ superfamily. Primers and regions used for PCR are shown. All sequence data were obtained from DNA data bank of Japan. Gaps in the alignment are represented by a dots. Amino acid residues identical to DjBMP are represented by a dash. Accession numbers are as follows: human TGF- $\beta 1$ (hTGFb1), Swiss-Prot/P01137; human TGF- $\beta 3$ (hTGFb3), Swiss-Prot/P10600; human inhibin- $\beta$ a (hINH-Ba), PIR/B24248; human inhibin- $\beta$ b (hINH-Bb), Swiss-Prot/P09529; human BMP-2A (hBMP2A), PIR/B37278; human BMP-3 (hBMP3), Swiss-Prot/P12645; human BMP-4 (hBMP4), PIR/C37278; human BMP-5 (hBMP5), PIR/A39263; human BMP-6 (hBMP6), PIR/B39263; human BMP-7 (hBMP7), PIR/C39263; human GDF-1 (hGDF1), PIR/C39364; human GDF-5 (hGDF5), PIR/JC2347; human Mullerian inhibiting substance (hMIS), PIR/A01397; Drosophila dpp (dDPP), PIR/A26158; Drosophila 60A (d60A), PIR/A43918; Xenopus Vg-1 (xVG1), PIR/A29619; sea urchin DVR-1 (suDVR1), PIR/S52408; sea urchin univin (suUNIVIN), GenBank/U10533; chicken dorsalin (cDORSALIN), GenBank/L12032; mouse nodal (mNODAL), PIR/S29718; ascidian BMPa (HrBMPa), Miya et al., 1996. 


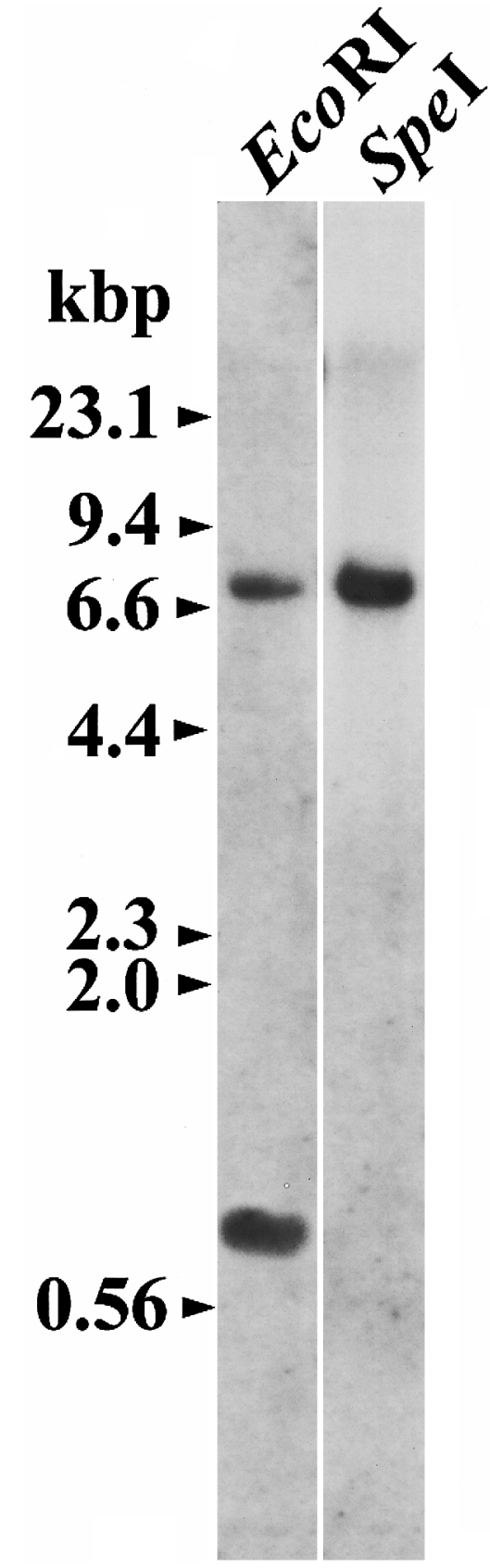

Fig. 3. Southern blot hybridization. Molecular size (Hindlll digested $\lambda$ DNA) is shown on the left.

expression in intact worm suggests that the molecule is important in maintenance of body plan and that the cellular and molecular events during regeneration themselves occur constantly in an intact body to maintain the body plan. This was also supported by the expression pattern of Hox/HOM-C genes along the antero-posterior axis of regenerating and intact body (Orii et al., in preparation).

Recently, De Robertis and Sasai (1996) proposed a hypothetical ancestral and primitive bilateral animal, Urbilateria, from which the arthropod and the chordate lineages diverged 600 million years ago, with Hox gene complexes, D-V patterning system by sog (short gastrulation)/chordin and $d p p /$
Bmp-4 and so on. In accordance with recent molecular evolutionary studies, the Urbilateria was divided into two groups, the Deuterostomia and the Protostomia. The Protostomia was further subdivided into the Lophotrochozoa and the Ecdysozoa during the evolution (for review; Balavoine and Adoutte, 1998). The Plathelminthes including Dugesia japonica has simple body plan and is grouped into the Lophotrochozoa. In this paper, we showed that the Plathelminthes also has BMP gene as well as the Deuterostomia (vertebrates etc.) and the Ecdysozoa (arthropoda, nematoda etc.). In addition to Hox gene complexes and Djbmp, the presence of DjotxA, DjotxB and Djotp which are planarian homologues to orthodenticle and orthopedia in Drosophila (Umesono et al., 1997 ; Umesono et al., 1998), strongly suggests that the basic body plan of the Bilateria including Deuterostomia, Ecdysozoa and Lophotrochozoa, are common. To date, the presence of BMP gene has not been reported in radiata hydrozoan such as hydra. BMP gene may be related to the establishment of $D-V$ axis in animal evolution.

We have no information on other BMP genes in the planarian. However, it has been suggested that BMP-4 forms a heterodimer with BMP-7 to function in mesoderm induction in Xenopus (Suzuki et al., 1997) and that DPP acts to establish $\mathrm{D}-\mathrm{V}$ pattern by forming a heterodimer with SCREW, a member of 60A subfamily, in Drosophila (Arora et al., 1994). DjBMP may also act with another unidentified BMP-like member in the planarian. In higher organisms, tolloid/Bmp-1 gene product also regulates $\mathrm{D}-\mathrm{V}$ patterning in relation to DPP/BMP and SOG/Chordin proteins (Marqués et al., 1997; Piccolo et al., 1997). To search for and analyze such molecules in planarians may help us to understand the evolution of the common mechanism of body patterning in the Bilateria.

\section{ACKNOWLEDGMENTS}

We thank Dr. Y. Umesono for whole mount in situ hybridization, Drs. T. Miya (Tokyo Inst. of Tech.) and N. Ueno (Natl. Inst. for Basic Biol.) for ascidian BMP sequence data, Dr. T. Katayama (Ushimado Marine Labratory, Okayama Univ.) and members of our laboratory for encouragement and discussion.

This work was supported by Grant-in-Aid for Encouragement of Young Scientists to H.O. (no. 09780688), Special Coordination Funds for Promoting Science and Technology to K.A. and Grant-in-Aid for Scientific Research on Priority Areas to K.W. (no. 09275224)

The nucleotide sequence data reported in this paper will appear in the $\mathrm{DDBJ} / E M B L / G e n B a n k$ nucleotide sequence databases with the accession number AB010966.

\section{REFERENCES}

Agata K, Soejima Y, Kato K, Kobayashi C, Umesono Y, Watanabe K (1998) Structure of the planarian central nervous system (CNS) revealed by neuronal cell markers. Zool Sci 15: 433-440

Arora K, Levine MS, O'Connor MB (1994) The screw gene encodes a ubiquitously expressed member of the TGF- $\beta$ family required for specification of dorsal cell fates in the Drosophila embryo. Genes Dev 8: 2588-2601

Baguñà J, Saló E, Romero R, Garcia-Fernàndez J, Bueno D, MuñozMármol AM, Bayascas-Ramírez JR, Casali A (1994) Regeneration and pattern formation in planarians: Cells, molecules and 

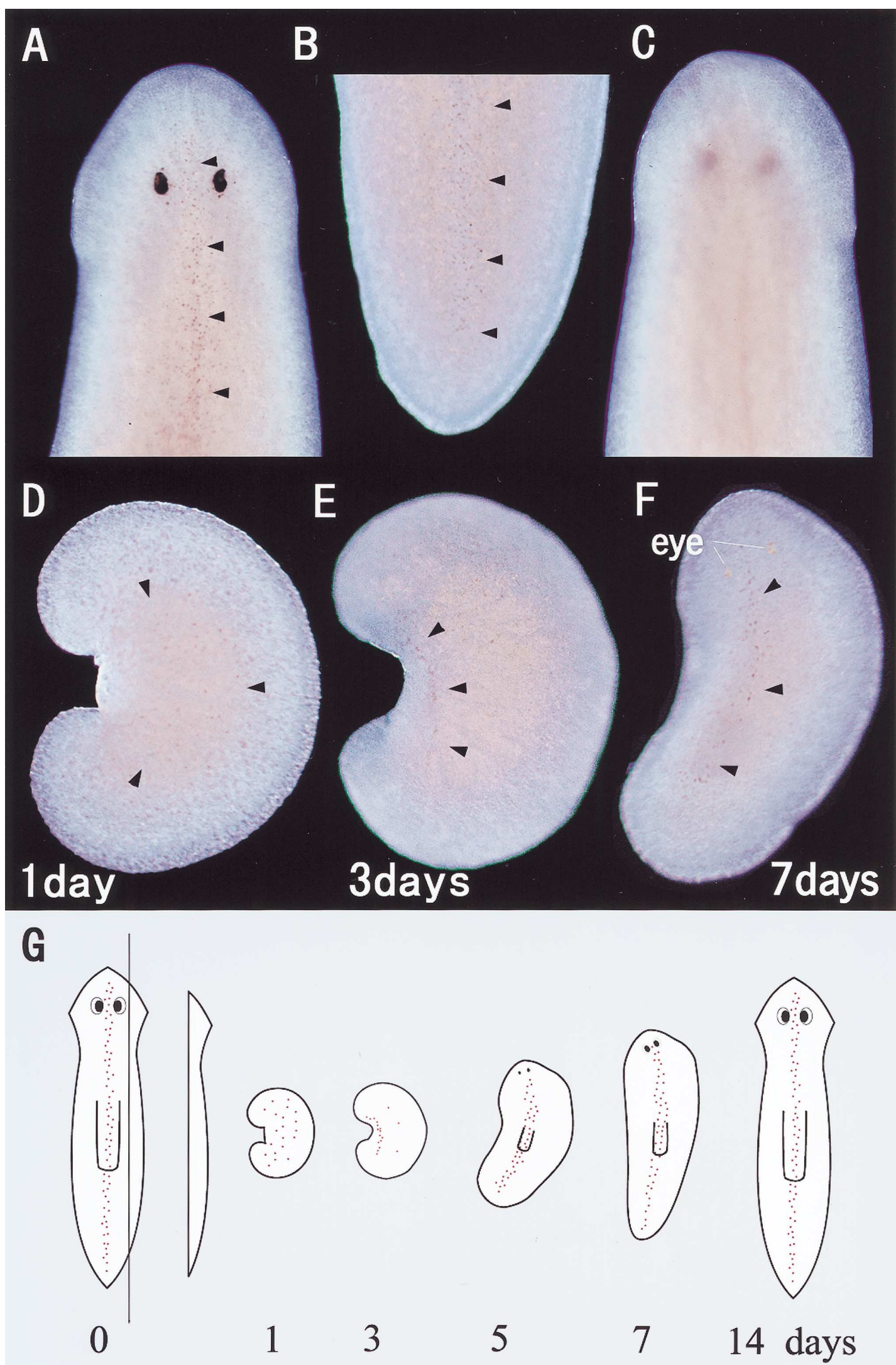

Fig. 4. Whole mount in situ hybridization. Anterior dorsal (A), posterior dorsal (B) and anterior ventral (C) view of intact worm. Dorsal view of regenerating marginal piece 1 day $(\mathbf{D}), 3$ days $(\mathbf{E})$ and 7 days $(\mathbf{F})$ after amputation. The region expressing $D j b m p$ is shown by the arrowheads. Schematic representation of expression of $D j b m p$ during regeneration of right marginal piece $(\mathbf{G})$. Dots show the expression of $D j b m p$. 
genes. Zool Sci 11: 781-795

Balavoine G, Adoutte A (1998) One or three Cambrian radiations? Science 280: 397-398

Dale L, Howes G, Price BMJ, Smith JC (1992) Bone morphogenetic protein 4: a ventralizing factor in early Xenopus development. Development 115: 573-585

De Robertis EM, Sasai Y (1996) A common plan for dorsoventral patterning in bilateria. Nature 380: $37-40$

Dosch R, Gawantka V, Delius H, Blumenstock C, Niehrs C (1997) Bmp-4 acts as a morphogen in dorsoventral mesoderm patterning in Xenopus. Development 124: 2325-2334

Holley SA, Jackson PD, Sasai Y, Lu B, De Robertis EM, Hoffmann FM, Ferguson EL (1995) A conserved system for dorsal-ventral patterning in insects and vertebrates involving sog and chordin. Nature 376: 249-253

Horgan BLM, Blessing M, Winnier GE, Suzuki N, Jones CM (1994) Growth factors in development: the role of TGF- $\beta$ related polypeptide signalling molecules in embryogenesis. Development 1994 suppl: 53-60

Horgan BLM (1995) Upside-down ideas vindicated. Nature 376: 210-211

Irish VF, Gelbart WN (1987) The decapentaplegic gene is required for dorsal-ventral patterning of the Drosophila embryo. Genes Dev 1: 868-879

Jones CM, Lyons KM, Lapan PM, Wright CVE, Horgan BLM (1992) DVR-4 (Bone Morphogenetic Protein-4) as a posterior-ventralizing factor in Xenopus mesoderm induction. Development 115: $639-647$

Kingsley DM (1994) The TGF- $\beta$ superfamily: New members, new receptors, and new genetic tests of function in different organisms. Genes Dev 8: 133-146

Kurihara T, Kitamura K, Takaoka K, Nakazato H (1993) Murine bone morphogenetic protein- 4 gene: Existence of multiple promoters and exons for the 5'-untranslated region. Biochem Biophys Res Commun 192: 1049-1056

Marqués G, Musacchio M, Shimell MJ, Wunnenberg-Stapleton K, Cho KWY, O'Connor M (1997) Production of a DPP activity gradient in the early Drosophila embryo through the opposing actions of the SOG and TLD proteins. Cell 91: 417-426
Miya T, Morita K, Ueno N, Satoh N (1996) An ascidian homologue of vertebrate $B M P s-5-8$ is expressed in the midline of the anterior neuroectoderm and in the midline of the ventral epidermis of the embryo. Mech Dev 57: 181-190

Nishimatsu S-i, Suzuki A, Shoda A, Murakami K, Ueno N (1992) Genes for bone morphogenetic proteins are differentially transcribed in early amphibian embryos. Biochem Biophys Res Commun 186: 1487-1495

Orii H, Agata K, Watanabe K (1993) POU-domain genes in planarian Dugesia japonica: The structure and expression. Biochem Biophys Res Commun 192: 1395-1402

Panganiban GEF, Rashka KE, Neitzel MD, Hoffmann FM (1990) Biochemical characterization of the Drosophila dpp protein, a member of the transforming growth factor $\beta$ family of growth factors. Mol Cell Biol 10: 2669-2677

Piccolo S, Agius E, Lu B, Goodman S, Dale L, De Robertis EM (1997) Cleavage of Chordin by Xolloid metalloprotease suggests a role for proteolytic processing in the regulation of Spemann organizer activity. Cell 91: 407-416

Sasai Y, Lu B, Steinbeisser H, De Robertis EM (1995) Regulation of neural induction by the Chd and Bmp-4 antagonistic patterning signals in Xenopus. Nature 376: 333-336

Suzuki A, Kaneko E, Maeda J, Ueno N (1997) Mesoderm induction by BMP-4 and -7 heterodimers. Biochem Biophys Res Commun 232: $153-156$

Umesono Y, Watanabe K, Agata K (1997) A planarian orthopedia homolog is specifically expressed in the branch region of both the mature and regenerating brain. Dev Growth Differ 39: 723727

Umesono Y, Watanabe K, Agata K (1998) Distinct structural domains in the planarian brain defined by the expression of evolutionarily conserved homeobox genes. Dev Genes Evol, in press

Watanabe K, Sakai F, Orii H (1997) Stepwise dilution screening of a cDNA library by polymerase chain reaction. Anal Biochem 252: 213-214

Wilson PA, Hemmati-Brivanlou A (1995) Induction of epidermis and inhibition of neural fate by Bmp-4. Nature 376 : 331-333

(Received July 23, 1998 / Accepted August 24, 1998) 